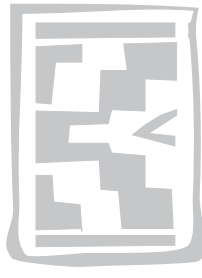

\title{
A retrospective longitudinal study of animal and human rabies in Botswana 1989-2006
}

\author{
K.T. MOAGABO ${ }^{1 *}$, K.B. MONYAME ${ }^{1}$, E.K. BAIPOLEDI ${ }^{1}$, M. LETSHWENYO ${ }^{2}$, N. MAPITSE ${ }^{2}$ \\ and J.M.K. HYERA ${ }^{1}$
}

\begin{abstract}
MOAGABO, K.T., MONYAME, K.B., BAIPOLEDI, E.K., LETSHWENYO, M., MAPITSE, N. \& HYERA, J.M.K. 2009. A retrospective longitudinal study of animal and human rabies in Botswana. Onderstepoort Journal of Veterinary Research, 76:399-407

A longitudinal study of animal and human rabies covering 18 years from 1989 to 2006 was retrospectively conducted in order to highlight the epidemiological features and trends of the disease in Botswana. Over the 18-year period, a total of 4306 brain specimens collected from various species of animals including human beings with clinical signs consistent with rabies were submitted to the National Veterinary Laboratory in Gaborone for confirmatory diagnosis. Of the samples submitted, 2419 cases were found to be positive for lyssavirus antigen; this presents an overall prevalence rate of $56.18 \pm 1.48 \%$. About $85.7 \%$ (2 074/2 419) of the cases were from domestic animals, $14.2 \%$ $(343 / 2419)$ cases were from wild animals and two cases $(0.1 \%)$ were from human beings. During the first half of the study (1989-1997) the prevalence rate of the disease was estimated at $62.79 \pm 1.85 \%$ (1 645/2 620 positive) whereas during the second half (1998-2006) it was estimated at $45.91 \pm$ $2.38 \%(774 / 1686$ positive) and the difference between the two estimates was statistically, highly significant $\left(\Delta \%=16.88, \mathrm{SE}_{(95)}\right.$ diff $\left.\%=3.015, \mathrm{SD}=5.599 ; P<0.001\right)$. Ruminant rabies accounted for $79.99 \%$ (50.92\% bovine, $28.40 \%$ caprine and $0.67 \%$ ovine) whereas canine (domestic dog) and feline (domestic cat) accounted for 16.01 and $0.87 \%$, respectively. Equine rabies accounted for $3.13 \%$ with 1.35 and $1.78 \%$, respectively, for horses and donkeys. Jackal rabies accounted for more than $60 \%$ of the total cases in wild animals. These findings are discussed in relation to the previous epidemiological situation of the disease (1979-1988), its socio-economic impact, monitoring and control in Botswana.
\end{abstract}

Keywords: Animal rabies, Botswana, domestic animals, longitudinal study, prevalence, retrospective, wild animals

\section{INTRODUCTION}

Rabies is a highly fatal viral disease of all warmblooded animals including man and is characterized clinically by a predominance of nervous signs and

* Author to whom correspondence is to be directed. E-mail: kmoagabo@gov.bw

1 Botswana National Veterinary Laboratory, Private Bag 0035 Gaborone

2 Department of Veterinary Services, Private Bag 0032, Gaborone, Botswana

Accepted for publication 16 April 2009-Editor change in behaviour (aggressiveness/madness), convulsions, coma and death. The word "rabies" is derived from the Latin word "rabidus", which means "mad" (Swanepoel 1994). Rabies virus belongs to the genus Lyssavirus in the family Rhabdoviridae (Andrewes, Pereira \& Wildy 1978; Swanepoel 1994). The epidemiology, pathogenesis, clinical signs, pathology, diagnosis and control of the disease has been cogently documented elsewhere (Swanepoel 1994).

In Botswana, rabies is commonly known as Molafo (Mushi 1995) and unconfirmed reports of the dis- 
ease date as far back as 1919 with outbreaks in dogs observed first in the southeastern district of Lobatse in 1919 and 1922, and then in the northwestern district of Ngamiland in 1936 (Swanepoel 1994). The outbreak of animal rabies in Botswana was confirmed for the first time in 1938 (Anon. 19321991); during an outbreak of dog rabies in the Ngamiland district. The disease has since then spread countrywide and has in addition to the domestic dog also affected domestic herbivores (cattle, goats and sheep) and several wild animals especially the carnivores (Mushi \& Diteko 1992; Swanepoel 1994; Anon. 1995-2006).

Rabies is a notifiable disease in Botswana and sporadic outbreaks of this disease continue to occur in the country virtually each year (Anon. 1995-2006). Mushi \& Diteko (1992) studied retrospectively the epidemiological situation of rabies in Botswana for a period of 10 years ranging from 1979-1988. In the current retrospective study we examine further the epidemiological trends of the disease, this time over a period of 18 years starting from 1989 to 2006.

\section{MATERIALS AND METHODS}

\section{Specimen collection and submission}

Brain specimens from animals suspected to have died due to rabies were collected by veterinary field staff, preserved in $50 \%$ glycerol saline, securely packed and submitted to the National Veterinary Laboratory (NVL) in Gaborone by air, rail or road. The NVL is the only facility in Botswana with capacity and capability to conduct confirmatory laboratory diagnosis of rabies in animals and humans. The specimens were each accompanied by a rabies notification and/or disease report form which captured inter alia the animal species from which the specimen was collected, the place of origin (district, crush, extension area), the particulars of the animal (e.g. breed, sex, age, rabies vaccination status) and the number of animals/humans the rabid animal was in contact with or had bitten.

\section{Fluorescent antibody test}

Impression smears from the medulla and hippocampus of the brain specimens were made on clean glass slide, air dried and fixed in cold acetone at $-20{ }^{\circ} \mathrm{C}$. Other impression smears from known rabies positive (field strain) and negative brain specimens were similarly prepared and fixed. All smears were stained by the direct fluorescent antibody test (FAT) method (Dean, Abelseth \& Atanasiu 1996) using an anti-lyssavirus fluorescein isotheocyanate (FITC) polyclonal conjugate produced by the OIE Rabies Reference Laboratory at Onderstepoort Veterinary Institute, South Africa.

\section{Mouse inoculation test}

In situations where the FAT yielded negative results the brain specimens were further processed for the biological mouse inoculation test (MIT). A $10 \%$ suspension $(\mathrm{w} / \mathrm{v})$ of the brain specimen was prepared in physiological phosphate buffered saline and then inoculated into 3-weeks-old laboratory mice which were kept under observation for clinical signs of rabies for a maximum of 30 days. At least four mice were used per case and each mouse was inoculated intracerebrally, after ether anaesthesia with $0.03 \mathrm{m \ell}$ of the brain suspension (Mushi \& Diteko 1992). Brains were harvested from mice that died within that period and examined for rabies viral antigen by the direct FAT.

\section{Statistical analysis}

Prevalence rates were used to estimate the amount of disease (rabies) in the animal population at a particular point in time and were determined by dividing the total positive specimens (as confirmed by FAT and MIT) by the total specimens tested (Thrusfield 1995) and were expressed as percentages. Relative frequencies were also calculated according to Thrusfield (1995) and were similarly expressed. The standard errors (SE) of the percentages at $95 \%$ confidence $\left(\mathrm{SE}_{95}\right)$ were calculated according to the method of Swinscow (1980). The table of Armitage (1971) was used to ascertain statistically the difference between prevalence rates. Variations in the number of rabies positive cases between years and between months were examined by analysis of variance using mean squares in a 2-way table (Snedecor \& Cochran 1980). Probability ( $p)$ values of $<0.05,<0.01$ and $<0.001$ were classified as significant, very significant and highly significant.

\section{RESULTS}

A total of 2419 of the 4306 (56.18 $\pm 1.48 \%)$ brain specimens were positive for rabies virus. Amongst the 2419 positive specimens were 2074 specimens $(85.7 \%)$ from domestic animals, 343 specimens from (14.2\%) from wild animals and two specimens $(0.1 \%)$ from human beings. Samples for each were submitted along with case history, and clinical signs exhibited by the animals before death. The signs observed in the cases confirmed positive for rabies 
TABLE 1 Clinical signs observed by the field staff in pet animals (dogs and cats) confirmed by the laboratory to be positive for rabies 1999-2006

\begin{tabular}{|l|c|c|}
\hline Clinical signs & Number of cases & Relative frequency (\%) \\
\hline Salivation & 15 & 4.155 \\
Aggressiveness & 30 & 8.310 \\
Paralysis & 7 & 1.939 \\
Abnormal behaviour & 3 & 0.831 \\
Incoordination & 7 & 1.939 \\
Continuous barking & 3 & 0.831 \\
Found dead & 4 & 1.108 \\
Other & 2 & 0.554 \\
No clinical signs specified & 290 & 80.332 \\
\hline Total & 361 & 100.000 \\
\hline
\end{tabular}

TABLE 2 Clinical signs observed by the field staff in small ruminants (sheep and goats) confirmed by the laboratory to be positive for rabies 1999-2006

\begin{tabular}{|l|c|c|}
\hline Clinical signs & Number of cases & Relative frequency (\%) \\
\hline Salivation & 22 & 7.143 \\
Aggressiveness & 16 & 5.195 \\
Paralysis & 11 & 3.571 \\
Abnormal behaviour & 8 & 2.597 \\
Incoordination & 49 & 15.909 \\
Continuous barking & 4 & 1.299 \\
Found dead & 2 & 0.649 \\
Other & 5 & 1.623 \\
No clinical signs specified & 191 & 62.013 \\
\hline Total & 308 & 100.000 \\
\hline
\end{tabular}

TABLE 3 Clinical signs observed by the field staff in cattle confirmed by the laboratory to be positive for rabies 1999-2006

\begin{tabular}{|l|c|c|}
\hline Clinical signs & Number of cases & Relative frequency (\%) \\
\hline Salivation & 64 & 13.675 \\
Bellowing & 47 & 10.043 \\
Aggressiveness & 62 & 13.248 \\
Paralysis & 9 & 1.923 \\
Incoordination & 19 & 4.060 \\
Found dead & 3 & 0.641 \\
No clinical signs specified & 264 & 56.410 \\
\hline Total & $\mathbf{4 6 8}$ & 100.000 \\
\hline
\end{tabular}

TABLE 4 Clinical signs observed by the field staff in wildlife species confirmed by the laboratory to be positive for rabies $1999-2006$

\begin{tabular}{|l|c|c|}
\hline Clinical signs & Number of cases & Relative frequency (\%) \\
\hline Decreased fear response & 18 & 25.352 \\
Aggressiveness & 9 & 12.676 \\
Wasting & 1 & 1.408 \\
Salivation & 1 & 1.408 \\
Paralysis & 1 & 1.408 \\
No clinical signs specified & 41 & 57.746 \\
\hline Total & 71 & 100.000 \\
\hline
\end{tabular}


Animal and human rabies in Botswana 1989-2006

TABLE 5 Prevalence rates of rabies in Botswana 1989-2006

\begin{tabular}{|l|l|l|l|}
\hline Year & $\begin{array}{l}\text { Number of specimens } \\
\text { tested }^{1}\end{array}$ & $\begin{array}{l}\text { Number of rabies positive } \\
\text { specimens }\end{array}$ & $\begin{array}{l}\text { Prevalence rate } \\
(\%) \pm \text { SE }^{2}\end{array}$ \\
\hline 1989 & 200 & 98 & $49.00 \pm 6.93$ \\
1990 & 392 & 258 & $64.80 \pm 4.73$ \\
1991 & 346 & 204 & $58.96 \pm 5.18$ \\
1992 & 329 & 203 & $61.70 \pm 5.25$ \\
1993 & 204 & 102 & $50.00 \pm 6.86$ \\
1994 & 310 & 179 & $57.74 \pm 5.50$ \\
1995 & 377 & 312 & $84.49 \pm 3.65$ \\
1996 & 197 & 122 & $61.93 \pm 6.78$ \\
1997 & 265 & 167 & $63.02 \pm 5.81$ \\
1998 & 350 & 227 & $64.86 \pm 5.00$ \\
1999 & 283 & 166 & $58.66 \pm 5.74$ \\
2000 & 190 & 99 & $52.10 \pm 7.10$ \\
2001 & 205 & 82 & $40.00 \pm 6.71$ \\
2002 & 158 & 63 & $38.87 \pm 7.60$ \\
2003 & 116 & 35 & $30.17 \pm 8.35$ \\
2004 & 96 & 23 & $23.96 \pm 8.54$ \\
2005 & 153 & 41 & $26.80 \pm 7.02$ \\
2006 & 135 & 38 & $28.15 \pm 7.59$ \\
\hline
\end{tabular}

1 Tested by FAT \& MIT

2 Standard error at $95 \%$ confidence

TABLE 6 Rabies confirmed cases by months in Botswana 1997-2006

\begin{tabular}{|c|c|c|c|c|c|c|c|c|c|c|c|c|}
\hline \multirow{2}{*}{ Month } & \multicolumn{10}{|c|}{ Number of cases per year } & \multirow{2}{*}{ SUM } & \multirow{2}{*}{ Mean } \\
\hline & 97 & 98 & 99 & 00 & 01 & 02 & 03 & 04 & 05 & 06 & & \\
\hline January & 10 & 15 & 17 & 13 & 14 & 1 & 6 & 1 & 2 & 2 & 81 & 8.1 \\
\hline February & 13 & 9 & 10 & 9 & 5 & 2 & 0 & 5 & 1 & 0 & 54 & 5.4 \\
\hline March & 8 & 24 & 6 & 8 & 8 & 5 & 1 & 3 & 0 & 0 & 63 & 6.3 \\
\hline April & 10 & 14 & 3 & 5 & 4 & 0 & 3 & 0 & 3 & 1 & 43 & 4.3 \\
\hline May & 9 & 17 & 13 & 10 & 7 & 8 & 0 & 1 & 3 & 6 & 74 & 7.4 \\
\hline June & 14 & 28 & 15 & 10 & 9 & 10 & 3 & 1 & 13 & 2 & 95 & 9.5 \\
\hline July & 11 & 31 & 17 & 11 & 8 & 9 & 7 & 0 & 8 & 5 & 107 & 10.7 \\
\hline August & 16 & 17 & 20 & 6 & 10 & 9 & 5 & 3 & 10 & 5 & 101 & 10.1 \\
\hline September & 14 & 24 & 17 & 6 & 2 & 3 & 5 & 0 & 5 & 4 & 80 & 8.0 \\
\hline October & 18 & 16 & 17 & 6 & 5 & 3 & 0 & 4 & 2 & 9 & 80 & 8.0 \\
\hline November & 21 & 18 & 18 & 10 & 8 & 8 & 4 & 4 & 3 & 3 & 97 & 9.7 \\
\hline December & 23 & 14 & 13 & 5 & 2 & 5 & 1 & 1 & 1 & 1 & 66 & 6.6 \\
\hline SUM & 167 & 227 & 166 & 99 & 82 & 63 & 35 & 23 & 41 & 38 & 941 & \\
\hline Mean & 13.9 & 18.9 & 13.8 & 8.3 & 6.8 & 5.3 & 2.9 & 1.9 & 3.4 & 3.2 & & 7.8 \\
\hline
\end{tabular}

TABLE 7 Variance analysis of the data presented in Table 2

\begin{tabular}{|l|c|l|l|l|}
\hline Source of variation & Degrees of freedom & Sum of squares & Mean of squares & Variance ratio (F) \\
\hline Years & 9 & 3649.909 & 405.55 & $33.406^{\star \star}$ \\
Months & 11 & 422.991 & 38.37 & $3.161^{\star \star}$ \\
Error & 99 & 1201.991 & 12.14 & \\
\cline { 1 - 3 } Total & $\mathbf{1 1 9}$ & $\mathbf{5 2 7 3 . 9 9 2}$ & & \\
\hline
\end{tabular}

${ }^{\star \star} P<0.01$ 
TABLE 8 Distribution of rabies positive cases by veterinary districts in Botswana 1989-2006

\begin{tabular}{|l|r|c|}
\hline Veterinary district & Number of rabies positive cases & Relative frequency (\%) \\
\hline Francistown & 411 & 16.99 \\
Gaborone & 61 & 2.52 \\
Ghantsi & 143 & 5.91 \\
Jwaneng & 124 & 5.13 \\
Kanye & 87 & 3.59 \\
Kasane & 6 & 0.25 \\
Letlhakane & 239 & 9.88 \\
Lobatse & 21 & 0.87 \\
Mahalapye & 145 & 5.99 \\
Maun & 163 & 6.74 \\
Mochudi & 66 & 2.73 \\
Molepolole & 73 & 3.02 \\
Nata & 5 & 0.21 \\
Palapye & 248 & 10.25 \\
Selibe Phikwe & 189 & 7.81 \\
Serowe & 341 & 14.10 \\
Shakawe & 7 & 0.29 \\
Tsabong & 90 & 3.72 \\
\hline Total & 2419 & 100.00 \\
\hline
\end{tabular}

TABLE 9 Distribution of rabies positive cases by domestic animal species in Botswana 1989-2006

\begin{tabular}{|l|l|c|}
\hline Species & Number of rabies positive cases & Relative frequency (\%) \\
\hline Dog & 332 & 16.01 \\
Cat & 18 & 0.87 \\
Cattle & 1056 & 50.92 \\
Goat & 589 & 28.41 \\
Sheep & 14 & 0.67 \\
Donkey & 37 & 1.78 \\
Horse & 28 & 1.35 \\
\hline Total & $\mathbf{2 0 7 4}$ & 100.00 \\
\hline
\end{tabular}

TABLE 10 Distribution of rabies positive cases by wild animal species in Botswana 1989-2006

\begin{tabular}{|l|c|c|}
\hline Species & Number of rabies positive cases & Relative frequency (\%) \\
\hline Jackal & 230 & 67.06 \\
Genet & 29 & 8.45 \\
Wild cat & 18 & 5.25 \\
Mongoose & 24 & 7.00 \\
Fox & 11 & 3.21 \\
Hyena & 10 & 2.91 \\
Honey badger & 7 & 2.04 \\
Duiker & 6 & 1.75 \\
Others\# & 8 & 2.33 \\
\hline Total & 343 & 100.00 \\
\hline
\end{tabular}

\# Rotel (3), squirrel (1), wild dog (2), springbok (1) and wild pig (1) 


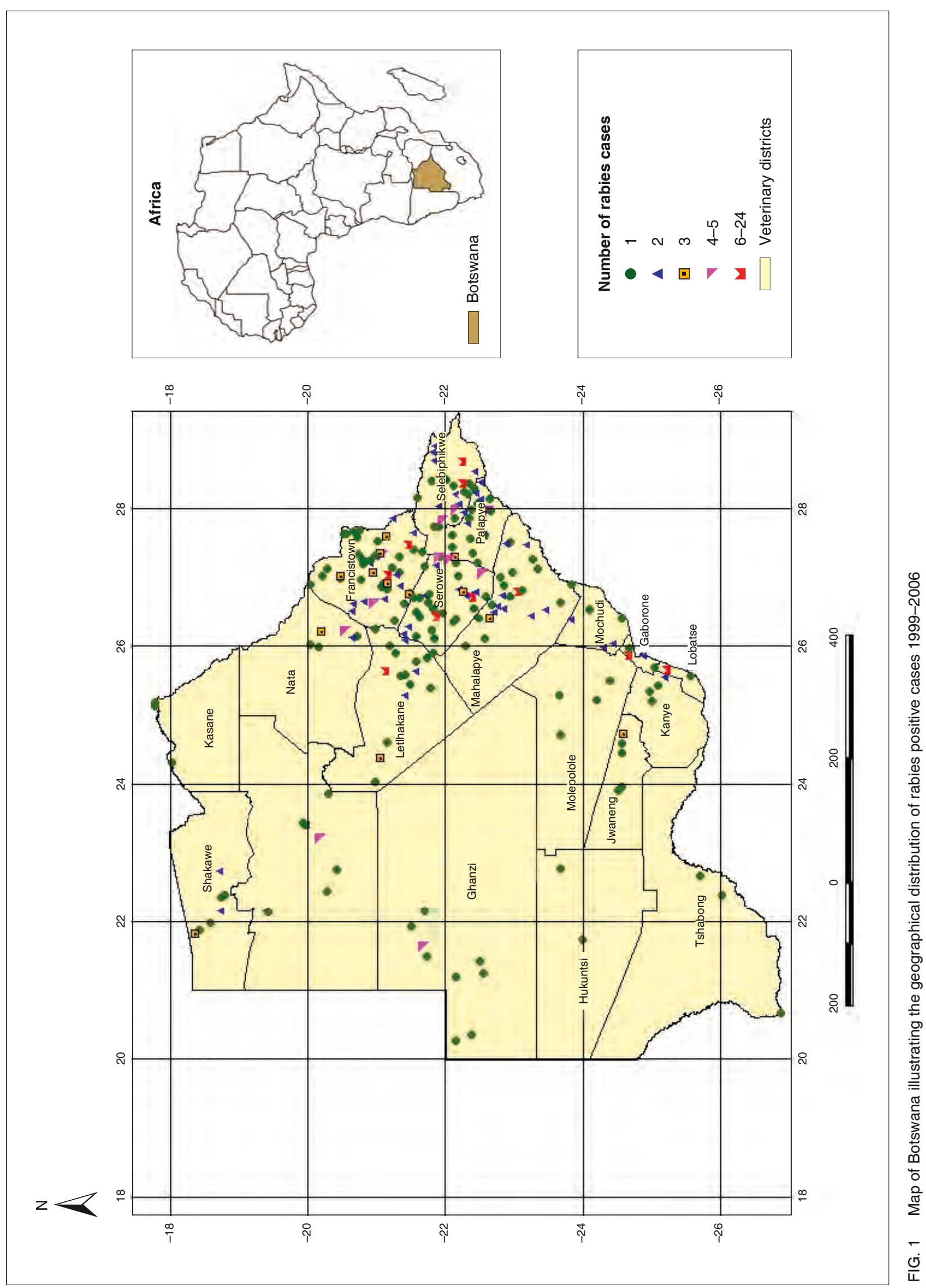


were summarized in Tables 1-4; the tables are selfexplanatory.

In over $50 \%$ cases, no clinical signs were described apart from stating a probable diagnosis of rabies. In dogs and cats aggressiveness and salivation were the most frequently observed clinical signs (Table 1). Aggressiveness, salivation and bleating were frequently observed in sheep and goats (Table 2). In cattle, salivation, aggressiveness and bellowing were the commonest clinical signs (Table 3) while in wildlife species decreased fear response and aggressiveness were the commonest clinical signs (Table 4).

Table 5 presents the prevalence rates (\%) of rabies by year; the prevalence rate was highest in 1995 and lowest in 2004 (Table 5). During the first period of the study (1989-1997) the cumulative prevalence rate was estimated at $62.79 \pm 1.85 \%$ (1 645/2 620 positive) while during the second period (1998$2006)$ it was estimated at $45.91 \pm 2.38 \%(774 / 1686$ positive). The difference between the two estimates was statistically, highly significant $(\Delta \%=16.88$, $\mathrm{SE}_{(95)}$ diff \% = 3.015, SD = 5.599; $\left.P<0.001\right)$.

Table 2 captures monthly rabies cases confirmed over a period of 10 years (1997-2006). On average, about eight rabies cases were confirmed each month ( $n=120$ observations); the mean number of cases ( $n=10$ observations) was highest in July and lowest in April (Table 6). There was a very significant variation in the mean number of cases both between the months and between the years (Table 7).

Table 8 exhibits the distribution of the rabies positive cases by districts and Fig. 1 illustrates geographically this distribution. The frequency of rabies positive cases was highest in Francistown and lowest in Nata district (Table 8).

Tables 9 and 10 show the distribution of rabies-positive cases, respectively in domestic and wild animal species. In domestic animals, ruminant rabies (bovine, caprine and ovine rabies) constituted $79.99 \%$ while canine (dog) and feline (cat) rabies accounted for 16.01 and $0.87 \%$, respectively. Equine rabies accounted for $3.13 \%$ with 1.35 and $1.78 \%$ occurring in horses (Equus caballus) and donkeys (Equus asinus), respectively (Table 9). In wild animals on the other hand, more than $80 \%$ of the cases occurred in jackals (Canis mesomelas), genet (Genetta genetta), yellow mongoose (Cynictis penicillata) and wild cat with jackal rabies accounting for more than $60 \%$ (Table 10).

\section{DISCUSSION}

Rabies, a disease of antiquity, is known to occur in two epidemiologic forms, namely urban and wildlife rabies (Acha \& Arambulo III 1985). These forms of the disease are also evident in Botswana. The domestic dog (Canis familiaris) is the principal reservoir transmitter of urban rabies; the maintenance of which constitutes essentially a dog-to-dog, dog-toother animals, and dog-to-human being cycle; with human beings as dead-end hosts. Wildlife or sylvatic rabies as it is sometimes called (Acha \& Arambulo III 1985), involves a broad spectrum of animal species in the wild; the principal reservoir transmitters in Botswana appear to be predominantly jackals, mongoose, genet and wild cats (Maganu \& Staugard 1985; Mushi \& Diteko 1992; Table 10).

The results presented in this study show a declining number of rabies cases in the domestic dog against a rising number of such cases in farm animals, particularly in cattle and goats (Table 9). Farm animals (including donkeys and horses) in Botswana are maintained in areas popularly referred to as "cattle posts", which are a distance away from human settlements (villages, towns and cities). Hence, in the absence of urban rabies which is principally associated with the dog in Botswana and elsewhere (Maganu \& Staugard 1985; Mushi \& Diteko 1992; Acha \& Arambulo III 1985) the rising cases observed currently in farm animals in this country, are most likely than not, result incursions of rabid wild animals into the so-called cattle posts. The jackal might possibly be contributing to rising rabies cases in the farm animals more significantly than the other species as judged by high relative frequency of the disease in this species in contrast to the other wildlife species (Table 10).

Studies by monoclonal antibodies on rabies virus isolates from Botswana have revealed the existence of two subtypes of the virus in this country; these subtypes have been termed canine and mongoose rabies (Tremlet, Wibberley \& King 1994). The canine rabies is found predominantly in the northern and western parts of the country and is related to the distribution of the domestic dog and the jackal. The rabies distribution map presented in this study (Fig. 1) also shows a higher number of cases in the northern and western parts of Botswana and these cases are probably also canine subtype in predominance. The mongoose subtype predominates the southeastern part of the country and has been associated with feline and viverrid wildlife (Tremlet et al. 1994). Earlier studies also by monoclonal antibodies on ra- 
bies isolates from the North West and Northern Cape Provinces of South Africa (these provinces share borders with Botswana) showed them to be of the mongoose subtype (King 1991). It is therefore inferred that the majority of the few rabies cases which occurred in south-east Botswana during 19892006 were also predominantly of the mongoose subtype and might have resulted from incursions of rabid viverrid wildlife into Botswana from the neighbouring provinces of South Africa where the problem of viverrid rabies is high (Swanepoel 1994).

Johnson, Letshwenyo, Baipoledi, Thobokwe \& Fooks (2004) have studied the molecular epidemiology of rabies in Botswana using nucleoprotein coding sequence data. They applied molecular phylogenetic techniques to a panel of rabies virus isolates $(n=$ 35 ) endemic in the country during 1988-1992; these isolates had previously been classified into two dominant subtypes (Tremlet et al. 1994). The studies were done in an attempt to compare the two typing techniques and to further investigate the virus/host species relationship in Botswana. The results have confirmed that the two subtypes are indeed two major groups and that they are related primarily to biotype. The wildlife-associated biotype (mongoose subtype) appeared more phylogenetically diverse and was more commonly isolated in the southeastern part, with the canine-associated biotype dominating the northern part of the country. These results concur with the findings of Tremlet et al. (1994).

Rabies has been and continues to remain a disease of considerable socio-economic and public health concern in most countries of Africa (Acha \& Arambulo III 1985). The economic impact of the disease in Botswana is seemingly not prodigious. For example, during 1989-2006, an average of 59 cattle and 33 goats died annually in the country, which is equated to a few thousands of Pula economic loss. The mean number of human deaths from the disease in Botswana during 1980-1983 was reported to be four deaths per year (Maganu \& Staugard 1985) and thereafter the mean number of death per year has declined virtually to zero, since for the entire period of 18 years (1989-2006) only two human deaths have been recorded and all occurred in the northern part of the country. This remarkable decline has been achieved from 1995 to 2004 mainly due to intensified control of urban rabies by vaccination of owned dogs, and destruction of un-owned, stray dogs supplemented by increased public awareness of the disease in animals and man (Table 5). This was then hampered by the continued outbreaks of foot-and-mouth disease that took all the resources that could had been otherwise used to control rabies (Table 5).

The control of urban rabies in most African countries is hampered by poverty, political conflicts and civil wars (Lawrence \& Foggin 1980; Fernandes \& Arambulo III 1985). The Republic of Botswana is both politically and economically stable and as such has the political will and resources (human and financial) to enable it to combat the disease. There are nevertheless some bottlenecks that appear in one way or another to hinder effective control of this disease in Botswana; these constraints seem to be associated mainly with inadequate understanding or knowledge about the ecology of the principal reservoir transmitter-the domestic dog. Essential ecological data need therefore be collected from various urban areas; these data should include inter alia information on pattern of ownership, relationship of animals to human society, population dynamics, structure (age, sex stratification) and turnover, habitat and relationship of dogs to other animals. These data will facilitate objective evaluation of the effectiveness of control programmes and should therefore be readily available at the start of the control programme.

\section{ACKNOWLEDGEMENTS}

We thank all laboratory technical staff of the Virology section at NVL who conducted the various diagnostic test methods sited in this publication. The map (Fig. 1) was prepared by Mr Anthony Dingalo and Mr Lengsen Habana of the Veterinary Epidemiology and Economics Section of the Department of Veterinary Services. To all those others, who helped in various ways, we record our gratitude. This paper is published by permission from the Director of Veterinary Services, Ministry of Agriculture, Republic of Botswana.

\section{REFERENCES}

ACHA, P.N. \& ARAMBULO III P.V. 1985. Rabies in the tropics history and current status, in Rabies in the tropics, edited by E. Kuwert, C. Merieux, H. Koprowski \& K. Boegel. Berlin: Springer-Verlag.

ANDREWES, C., PEREIRA, H.G. \& WILDY, P. 1978. Viruses of vertebrates, $4^{\text {th }}$ ed. London: Bailliere Tindall.

ANONYMOUS 1932-1991. Unpublished records. Veterinary Institute, Onderstepoort 0110.

ANONYMOUS 1995-2006. Annual reports. Gaborone: National Veterinary Laboratory, Ministry of Agriculture.

DEAN, D.J., ABELSERTH, M.K. \& ATANASIU, P. 1966. The fluorescent antibody test, in Laboratory techniques in rabies, $4^{\text {th }}$ 
edition, edited by F.X. Meslin, M.M. Kaplan \& H. Koprowski. Geneva: World Health Organization.

FERNANDES, M.K. \& ARAMBULO III, P.V. 1995. Rabies as an international problem, in World's debt to Pasteur, edited by H. Koprowski \& S.A. Plotkin. New York: Alan R. Liss, Inc.

JOHNSON, N., LETSHWENYO, M., BAIPOLEDI, E.K., THOBOKWE, G. \& FOOKS, A.R. 2004. Molecular epidemiology of rabies in Botswana: a comparison between antibody typing and nucleotidesequence phylogeny. Veterinary Microbiology, 101:31-38.

KING, A.A. 1991. Studies of the antigenic relationship of rabies and rabies-related viruses using anti-nucleoprotein monoclonal antibodies. Ph.D. Thesis, University of Surrey, UK.

LAWRENCE, J.A., FOGGIN, C.M. \& NORVAL, R.A.I. 1980. The effects of war on the control of diseases of livestock in Rhodesia (Zimbabwe). The Veterinary Record, 107:82-88.

MAGANU, E.T. \& STAUGARD, F. 1985. Epidemiology of rabies in Botswana, in Rabies in the tropics, edited by E. Kuwert, C. Merieux, H. Koprowski \& K. Boegel. Berlin: Springer-Verlag.
MUSHI, E.Z. 1995. Rabies, in Infectious diseases of livestock in Botswana. Gaborone: Botswana Government Printers.

MUSHI, E.Z. \& DITEKO, T. 1992. Epidemiological situation of rabies in Botswana in the period 1979-1988. Bulletin of Animal Health and Production in Africa, 40:111-113.

SNEDECOR, G.W. \& COCHRAN, W.G. 1980. Statistical methods, $7^{\text {th }}$ ed. Ames, lowa: lowa State University Press.

SWANEPOEL, R. 1994. Rabies, in Infectious diseases of livestock with special reference to Southern Africa, edited by J.A.W. Coetzer, G.R. Thomson \& R.C. Tustin. Cape Town: Oxford University Press.

SWINSCOW, T.D.W. 1980. Statistics at square one. London: British Medical Association.

THRUSFIELD, M. 1995. Veterinary epidemiology, $2^{\text {nd }}$ ed. London: Blackwell Scientific Publication.

TREMLET, J.G., WIBBERLEY, G. \& KING, A.A. 1994. Rabies virus typing - preliminary survey in Botswana. Tropical Animal Health and Production, 26:157-160. 